\title{
Review and Prospects of the Research of Forensic Linguistics in China
}

\author{
Jie Gao \\ Collage of Law and Humanities, Tianjin Polytechnic University \\ Tianjin 300387, China \\ E-mail: gjgj022@163.com
}

\begin{abstract}
This paper discusses forensic linguistics research in China from theoretical aspects and practical aspects combining with judicature, as well, gives a brief overview of foreign forensic linguistics research. Based on this, the summary of weaknesses existing in Chinese forensic linguistics studying is given. Finally, it carries on the outlook from three aspects in Chinese forensic linguistics research, which are theory constructing, methodology, practice and application.
\end{abstract}

Keywords: Forensic linguistics, Legal language, Review, Prospect

Forensic Linguistics, as a new subject, its rising and developing in China is just for more than 20 years. The basic theories and research approach are also at the stage of exploring. Compared with foreign nations, the contents of research in China seem narrower, the research approach is more outmoded too. In recent years, forensic linguistics in China is affected by research abroad gradually, all expand to some extent on basic theories and research approach.

\section{Overview of Domestic Forensic Linguistics Studying}

In recent 20 years, Academic circles have published more than 20 books and a number of academic papers on forensic linguistics studying. Overall, it concentrated in the following two areas.

\subsection{Theoretical research on Forensic Linguistics}

Theoretical research, which is the focus of Forensic Linguistics research in recent 20 years, involves mainly the following four issues.

\subsubsection{About the Subject Orientation, contents and methods}

Since Chen Jiong (1985) has proposed the establishment of Forensic Linguistics in 1985, Chinese scholars researched deeply on the subject system of Forensic Linguistics. Liu Suzhen (2002) argued that the subject orientation of forensic linguistics should take the basic point on its studying object, the relationship between law and language. Du Jinbang (2000) stated that the forensic linguistics had different research objects with linguistics and law, its theoretical principles also had their own characteristics, including application, realistic, systematic, inclusive and authoritative, etc. These were the important principles that should be paid more attention in building subject of forensic linguistics. Because of inclusiveness, its research areas were more extensive, there were many closely related subjects, and there were many theoretical and practical research branch. In practical research, studying of court language occupied the central position. Because of inclusiveness, the research methods were diversified, including the comparison, analysis, synthesis, statistical and corpus methods. In his article On Research and Development of Forensic Linguistics, Du Jinbang (2003) pointed out three tasks and the division of the main contents, including theoretical research (legal language and philosophy, legal pragmatics, legal language and culture, etc.) and applied research (the language of the court, the court translator, expert testifying, etc.). Li Zhenyu (2006) argued that the forensic linguistics neither belonged to linguistic nor science of law, it could not become an independent subject within a short time, but rather belonged to the interdisciplinary subject of law.

\subsubsection{Features on legal language}

Including the type of writing and style, vagueness and certainty of legal language, non-standard phenomena in Legal language, characteristics of legal language and legal words.

(1) Legal Type of Writing, Style, and Rhetoric 
Chen Jiong (1995) analysed three main characteristics of the legislative language: solemnness, rigorousness, and plain. He put forward that applying of legislative language should be vested in the areas of legislative technic. Pan Qingyun (2004) held that as a technical language different from the natural language, legal language has emerged as some characteristics different from other languages in the speech level and the level of expression. In particular, he studied features of some legal type of writings, such as legislative, judicial, tribunal questioning, court hearing, investigation, litigation, etc.

(2) Certainty and Vagueness of Legal Language

Du Jinbang (2001) noted that, legal language with the feature of vagueness while the judicial results requiring it to be certainty poses us with the contradiction between vagueness and certainty. On what kind of level can we solve the problem of transiting from vagueness to certainty may be an important issue researchers should concern. He analysed the eliminating process of the legal language from following aspects: relationship between certainty and vagueness, reasons of existence for vagueness, eliminating of vagueness, shows of the certainty of judicial language, the characteristics of language applying in Court activities, etc. From his point of view of practical application, Pang Jianrong (2003) analysed some reasons of the existence of vague terms in legal language, including that legislative principle required that legal language has a strong generalizability, applying of the evaluable words, the main differences of cognitive subjects. Also he analysed scopes of application of the vague words in legal language, such as expressing predictable contents and plots, expressing time or space difficult to determine, number and frequency do not need describe accurately, expressing facts and conditions not suitable to say directly, and the part of reasons of indictment and verdict, etc. Based on cognitive linguistics, rhetoric, legal pragmatics, Dong Xiaobo (2005) discussed the pragmatic functions that in certain circumstances, using of vague words could not only play an irreplaceable role in using of precise words, but also to make more precise. Through his analysis of the legislative language, Zeng Zhiyong (2007) found that precise legal words were more widely distributed in the procedural law, but vague legal words mainly in substantive law.

\section{(3) Standardization of Legal Language}

From aspect of rules of language, Xie Ying (2004) put forward a number of questions to Criminal Law of the People's Republic of China and put forward her own advices. From the current situation of legislation, judicature and administrative law enforcement, Ji Mingzhu (2005) analyses problems on legislative language, judicial and administrative execution language, standardization of legal oral language. In order to solve problems in legislative language, he suggests that we may begin with following four aspects: language conflict, language logic, language structure, language style. The misunderstanding of administrative execution and judicial language consist in three aspects: the mixed type of writing, language contaminant, language ambiguity. It may be solved if carrying out as following: using Chinese characters correctly; using correct words order; using rhetoric correctly; using neutral words in law-enforcing and judicature. As to the essential requirements for standardization of legal oral language, it should accord with standards of law and language, fit in with dual demands of written and oral language, do one's best to smooth the sense of language, and prevent from arising language discrimination.

(4) Features of Legal Words and Phases

By reviewing the characteristics and unique manner of expression, as well as the distinguishing features on using of legal language, Luo Hongxia (2001) discusses the feasibility of simplifying legal language, holds that it should be based on the reader and simplifying of legal language is still imperative. Chen Jiong (2003) specifically states a number of issues on naming and selecting and using of legal terms that should be noted, including its features of the age, its national characters, and the rules of according with structure of Chinese and language habits of Chinese people. In addition, he emphasizes the features of single meaning, causality, popularity, and blending harmoniously in structure, etc.

\subsection{Practical Research on Forensic Linguistics Combining With Judicature}

At present, this is a hot point abroad. While scholars in China have begun research in this area, but few. The efforts should focus on practical research combining with judicature for the future.

\subsubsection{Forensic Linguistics research based on analysing of speech acts}

Zhang Xinhong (2000) tried to combine foreign theories with Chinese practice on forensic linguistics. According to whether there are performative verbs or not, and whether the illocutionary force is strong or weak, legal speech acts are classified into three types: explicit, conventionalized and implicit. Following this analytical framework, Zhang Xinhong discussed the general pragmatic principles and the features of forensic language and the theories related to legal speech acts, analysed the functions and classification of legal speech acts. He 
conducted an investigation into the implementation in Chinese legislative discourses, as well as the classification and distribution of kinds of speech acts. It is good to combine with theory of linguistics and practice of Chinese. Chen Qiqing (2006) held that any regulation is a kind of speech act, so it has certain constitutive rules. Avoidable losses in some laws and regulations are often seen, because it lacks awareness of constitutive rules of legal speech acts.

\subsubsection{Research on Courtroom Language}

Liao Meizhen (2004) reveals the important role of Questions and Answers (Q \& A) activity in the trial by analysing the distribution of the Questions acts. It gives a great inspiration to the studying of Chinese forensic linguistics. It accords with the tide and trend of research of Chinese forensic linguistics. It has brought a new angle of view and a broader field of vision to forensic linguistics studying.

\subsubsection{Construction of Corpora}

Feng Pengcheng (2005) holds that firstly, a legal corpus of written language should be established, and makes use of it to divide words automatically and tag part-of-speech by machine; secondly, all words of the legal corpus should be carried on term frequency count, and graded according to five frequentness division method; thirdly, the basic vocabulary of legal language should be classified into three categories, namely, legal terminologies, basic legal expressions, and commonly used words of legal register; lastly, according to research results to extract customary expression in legal register.

\section{Brief Overview of Foreign Forensic Linguistics Research}

\subsection{Historical Retrospect on Foreign Forensic Linguistics Research}

Forensic linguistics originates from categories of science of law and linguistics, it covers all relative research on law and linguistics intersection field. As early as in the Greek time, the Western country's scholar already started to begin even studies in the legal language use. At that time studied, the focal point was lawmaking language and legal texts, it was closely related with the rhetoric. And, the representative work was The Language of the Law, written by David Mellinkoff. This book had a systematically discussion on historical origin, development and transmutation of UK-US legal language. In the 1960s, along with the linguistics research area widening day-by-day, more and more sociologists, linguists, psychologists and the legal scholars realized the crucial role of language in judicial proceedings, and joined the ranks positively to research forensic linguistics.

In July, 1993, the first congress of International Association of Forensic Linguists(IAFL) convened in the German Bonn. It marks birth of the first international professional academic organization of language and law. Thereafter, there was an increased upsurge of studying legal language. Along with Forensic Linguistics-The International Journal of Speech, Lan-guage and the Law began publication in 1994, the forensic linguistics has formed a new discipline different with other linguistic branches. In the following ten years, research and practice to forensic linguistics in western foreign language world showed a breathtaking speed of development and potential.

Overall, the study abroad after 1970s stressed on the extemporaneous words and the corpus analysis in the legal practice application. Besides continues to study theoretical foundation, legal text and syntax system, western scholars start to discuss issues from oral interactive aspects of courtroom words and legal activities. It has a strong practicability and well targeted. Since the beginning publication of Forensic Linguistics, content of articles has involved many aspects of courtroon language. Moreover, speeches of overseas scholars in all previous years IAFL congress are also primarily about the language evidence and the spoken language, seldem mention legal clauses and written languages.

In the recent 30 years, western scholars have brought this discipline enormous vitality. The researchers of different subjects get merits from the others, and write books and establish theories. Among them, the following books have a great influence: Language in the Judicial Process (Levi \& Walker, 1990); Language Crimes-The Use and Abuse of Language Evidencr in the Courtroom (Shuy, 1993); Language and the Law (Gibbons, 1994); Just Words: Law, Language, and Power (Conley \& O’Barr,1998); Legal Language (Tiersma,1999).

\subsection{Major Aspects of Foreign Forensic Linguistics Research}

About foreign forensic linguistics studying, the progress of was rapid, the research areas and aspects were extremely widespread. From a legal department of view, including criminal law, civil law, contract law, trademark law, etc. From the linguistic point of view, including courtroom words, translation in courtroom, analysis on legal documents, construction of a legal corpus, expert giving evidences, legal multi-language and bilingual research, etc. 


\section{Weaknesses in Chinese Forensic Linguistics Research in Comparison with Foreign Country}

As a new discipline, over the past 10 years, some progress has been made on our forensic linguistics research, and it has become an important branch of applied linguistics. However, there are still so many problems and weak points which we should think carefully.

\subsection{Starting Late and not Showing Its Due Discipline Superiority}

Applied linguistics research in China started in the late 1970s and early 1980s. In the 1990s, it got a certain degree of development. As for the research of forensic linguistics, it is even more weak, compared with similar studies abroad. In contemporary western, on forensic linguistics research, the development is rapid, and it involves a wide range, the research results are plentiful. Furthermore, it has specialized academic organizations and independent journals. While in China currently, the published books are few, published papers are very limited. Research achievements and progress can not meet the needs of judicial practice. So the further research remains to be done.

\subsection{Widening Research Scope but not Enough in Depth}

Such as Liao Meizhen had stated (2004), the foreign forensic linguistics research can be divided two stages, before 1970s and after 1970s. The first stage carried on the research of lawmaking language and legal texts (characteristics of sentence structure and vocabulary), focused on the static state characteristic of the legal language. After 1970s, focuses turned to dynamic studying on pragmatic research and discourse analysis. But the present research in China, in general, it still remains in the first phase of the study abroad, focusing on the introduction of foreign results and analysis of written materials. Many aspects of the research is not deep, such as the important branch of western forensic linguistics - legal phonetics and speech recognition in the application of judicial practice, etc. Although some aspects of the research have been involved, but not enough in-depth study, it also fails to reach consensus. Such as analysis on Q \& A activity in trial court, many scholars are discussed from different angles and explore and put forward some good suggestions, but it has not yet formed a kind of unified theory which can guide the judicial practice. Others, such as Dubi Yu (2003), Guo Qiang (2004), they have already done the quest work of the first step in the course constitution, the development mode of the university legal English teaching. Its meaning is very profound, but still can't resolve that problem completely, it needs more scholars to participate the research and promote the development together.

\subsection{Concentration of contents but unbalance in each part}

At present, domestic research is relatively concentrated in introduction of results abroad and lawmaking languages. Many of our works are the two aspects of the research. The main reason may lie in the late start in China. So the introduction can guide domestic scholars to grasp the trend and situation of this discipline, and it is helpful to establish theoretical system suitable for Chinese national conditions. As to focus on lawmaking language, it reflects the problem of emphasis on theoretical research but light of practice.

\section{Prospects of Forensic Linguistics Research in China}

\subsection{Aspect of Theoretical construction}

On the basis of the full development of the law and linguistics, the forensic linguistics will establish a complete theoretical system. It will contain rich contents, broad applicability, and it will greatly promote the development of legal practice research. The researchers should pay more attention to the related disciplines and make a reference to its theories, methods and results. Remarkably, domestic researchers have begun to apply linguistic theories to legal research, such as pragmatics and discourse analysis.

\subsection{Aspect of Methodology}

It is suggested that corpus should be established and relied on. Just as advocated by Coulthard (1994), corpus will be a necessary tool and play an important role in the forensic linguistics research. The development of corpus linguistics not only provides corpus which can be used to analyse and comparison, but also new research methods. What is gratifying now, there are domestic scholars engaged in building a database of legal corpus, such as Gu Yueguo, Du Jinbang, Liao Meizhen and Song Beiping and others. This would solve the problem that it can not access the plight of breakthrough development for a few decades only due to lack of corpus as a tool. Now it has already made staged achievements.

\subsection{Aspect of Practice and Application}

Foreign judicial practice provides a lot of valuable experiences. It has become common for foreign legal linguists to participate in hearing case directly. And the conclusion that they concluded has high reliability. Few domestic legal linguistic experts are involved in hearing controversial cases in language. Usually the interpretation and 
determination are drawn by legal experts, investigators and other legal professional. With the Evidence System improvement, more and more legal linguists will provide expert evidence for controversial cases in language, and provide language consulting services for legal profession. Forensic linguistics is improving daily, it will effectively update contents of language teaching in universities, colleges and departments of law and political science. It will be helpful to enhance communication among teaching, legislation and judicial practice.

What is gratifying now, it began to call scholars who studied forensic linguistics to participate in legislation and judicial practice. In 2007, the Legislative Affairs Commission of National People's Congress organized a group of legislative language advisory experts to read and revise draft laws before the vote. This aroused the enthusiasm of the researchers in legal language, and made them feel a sense of reality. More importantly, the draft laws provided valuable and lively materials for researchers, and made their research more pragmatic. This will be the great power of encouraging scholars to research forensic linguistics. Meanwhile, with the gradual deepening of research, academic groups will continue to grow, education in forensic linguistics has shown a good momentum of development.

\section{References}

Chen, Jiong. (1985). Forensic linguistics should be established. Modern Law Science, 1, 77.

Chen, Jiong. (1995). About the lawmaking language. Applied Linguistics, 3, 34-37.

Chen, Jiong. (2003). Naming and Selecting of Legal Terms. Rhetoric Learning, 6, 38-39.

Chen, Qiqing. (2006). On Absence of "Source of Law Clause" From Constitutive Rules of Speech Acts. Rhetoric Learning, 4, 58-60, 80.

Coulthard, M. (1994). Advances in Written Text Analysis. London Routledge.

Dong, Xiaobo. (2005). The Pragmatic Functions of The Fussy Legal Language. Journal of Shandong Institute of Commerce and Technology, 2, 73-75, 101.

Du, Biyu. (2003). Tentative Thoughts on the Course Design for Court Interpreting. ShanDong Foreign Language Teaching Journal, 1, 109-112.

Du, Jinbang. (2000). The Macrostructure of Forensic Linguistics: An Overview Based on Current Researches. Modern Foreign Languages, 1, 99-107.

Du, Jinbang. (2003). On Research and development of Forensic Linguistics. Journal of Guangdong University of Foreign Studies, 1,14-17.

Du, Jinbang. (2001). The Transition from Uncertainty of Legal Language to Certainty of the Judicial Result. Modern Foreign Languages, 3, 305-310.

Feng, Pengcheng. (2005). Setting up legal corpus base and measuring research to its vocabulary. Master's thesis of Nanjing Normal University.

Guo, Qiang. (2004). Motivations of and Approaches to the Curriculum Development of English for Law, ShanDong Foreign Language Teaching Journal, 1, 67-70.

J. Gibbons. (1994). Language and the Law. Longman: London, pp. 476.

Ji, Mingzhu. (2005). Discussions on the Standardization of the Legal Language. Master's thesis of Suzhou University.

John M. Conley and William M. O'Barr. (1998). Just Words: Law, Language, and Power. University of Chicago Press.

Levi, Judith N. and Anne Graffam Walker. (1990). Language in the Judicial Process. New York: Plenum Press.

Li, Zhenyu. (2006). On the subject ascription of forensic Linguistics. Jiangxi social science, 10, 211-214.

Liao, Meizhen. (2004). A Review of study of forensic linguistics abroad. Contemporary linguistics, Vol. 6, No. 1, 66-76.

Liao, Meizhen. (2004). The Principle of Goal and Goal Analysis and Cooperation in Verbal Interaction. Foreign Language Research, 5, 43-52.

Liu, Suzhen. (2002). Subject Orientation of Forensic Linguistics - the relationship between language and the law. Journal of Shanghai University of Political Science \& Law, 3, 49-53.

Luo, Hongxia. (2001). An exploration of the feasibility in simplification of forensic language. Journal of College of Chinese Language and Culture of Jinan University, 4, 73-77. 
Mellinkoff, David. (1963). The language of the law. Boston: Little, Brown and Company.

Pan, Qingyun. (2004). Law Language is a Technical One Different From National Language. Journal of Jianghan University (Humanities Sciences), 2, 18-22.

Pang, Jianrong. (2003). Pragmatic Vagueness in Law Language. Foreign Language and Literature Studies, 4, 54-57.

Shuy, R. W. (1993). Language Crimes-The Use and Abuse of Language Evidence in the Courtroom. Blackwell, Oxford.

Tierma, Peter M. (1999). Legal Language. University of Chicago Press.

Xie, Ying. (2004). The Analysis of Some Language Expressions of the Punishment of PRC. Journal of Quanzhou Normal University, 1, 42-46.

Zeng, Zhiyong.(2007). Imparallel Attribution of Bi-dimensionality of legal language. Journal of Hubei Institute of Education, 2, 75-77.

Zhang, Xinhong. (2000). An Analysis of the Speech Acts in Chinese Legislative Discourses. Modern Foreign Languages, 3, 284-295. 